\title{
TECHNOLOGY IS TOO IMPORTANT TO LEAVE TO TECHNOLOGISTS
}

\author{
Jeremy Dunning, Indiana University and Arjuna Multimedia \\ Richard Rogers and Richard Magjuka, Kelley School of Business, Indiana University \\ David Waite, Butler University \\ Keith Kropp and Thomas Gantz, Kendall-Hunt Publishers \\ Abtar Kaur, Open University Malaysia \\ Ari Vidali, Envisage \\ Tom Hunt and Larry Vandermolen, Indiana University
}

\begin{abstract}
The TALON/nPower learning object suite, developed by Arjuna Multimedia, is a set of 39 repurposeable learning object templates based on styles of teaching and learning that are designed to allow instructors and designers to create substantive learning objects without changing any of the source code. The instructor or designer can use the templates to design a new learning object without writing or changing any source code. The templates are simple enough that instructors with little or no programming experience can create their own learning objects. This paper examines the experiences of two professors' use of the templates to create interactive exercises for their courses.
\end{abstract}

\section{KEYWORDS}

Repurposeable learning objects, Learning styles, Teaching styles, Learning effectiveness, Cost effectiveness

\section{INTRODUCTION}

"War is too important to leave to the generals," Georges Clemenceau, Prime Minster of France during the First World War, once stated. This sentiment can also be applied to the use of technology in education. If the process of creating technology-mediated education is not open to, and controlled by, the instructor, it does not best serve the purposes of education. This means that the instructor with little or no experience in programming must be able to understand and to use technology tools without having to understand the technical aspects of those tools.

One of the struggles faced in distance education and technology-mediated instruction is providing interactive and highly experiential learning exercises. Learning objects are interactive exercises that allow the student to use the content learned in a particular part of a course and; (1) demonstrate mastery of the content, (2) apply that knowledge to solving a problem, and (3) use the content in a critical thinking exercise that allows the student to place the content within the context of the larger course topic.

There are two problems associated with learning objects. The first is that they require some multimedia programming, and they are, therefore, beyond the abilities of typical instructors, who may only be capable of creating course support materials within simple systems like Blackboard, WebCT, and PowerPoint. The other drawback is that if these objects are created from first principles each time, the cost of providing substantive interactive learning objects may be prohibitive. In part, the cost is related to the fact 
that the programmers and instructional designers may not know a great deal about the subject matter, and the instructors may know little about multimedia design and programming. Both groups therefore operate within their own area of comfort, and there is little real communication outside of those areas.

It is clearly impractical to teach each instructor about multimedia programming and teach each programmer about specific subject matter areas. What is practical is to define learning objects in terms of the styles in which we teach and learn. All of us understand how we learn, and there are a limited number of learning styles. Educators tend to teach to those learning styles, consciously or not, because they know from experience that teaching styles that are linked to the ways in which students learn are most effective. If we were to define learning objects more in terms of the teaching and learning styles the objects utilize and less in terms of the specific content or programming strategy, programmers and instructors could more clearly understand each other and the role each plays in the design process. The instructor can be more involved in the design of the learning objects if the objects are defined in terms of a context (teaching and learning styles) that he or she can understand. Developing a common language of design cuts the cost of developing individual learning objects; however, the cost remains high if each object is designed from scratch. It also allows designers and programmers to move from content area to content area using the same nomenclature and design principles because teaching and learning styles are independent of topic area.

If learning objects are defined in terms of a limited number of teaching and learning styles, they are independent of content area to a great extent. We should therefore be able to create templates for learning objects that are based on learning or teaching styles. The templates would be designed so that they could be reprogrammed for any content area at minimal expense. This would allow instructors to design learning objects for their courses using most of the existing code for the template. A multimedia programmer would then insert the graphic and text elements required to complete the learning object in the design executed by the instructor. In most cases less than $5 \%$ of the code for the template would need to be rewritten each time the learning object is reconfigured.

The TALON/nPower learning object suite, developed by Arjuna Multimedia, is a set of 39 repurposeable learning object templates based on styles of teaching and learning that are designed to allow instructors and designers to create substantive learning objects without changing any of the source code. The templates are simple enough that instructors with little or no programming experience can create their own learning objects. For more information about the TALON/nPower Learning Object Suite, please visit: http://www.indiana.edu/ scstest.jd.learningobjects.htm.

In this paper we will examine the experiences of two professors' use of the templates to create interactive exercises for their courses. The professors were given access to the entire TALON/nPower learning object suite and were asked to design learning objects with any of the templates they wished to use. The two courses involved are an introductory level public speaking course, designed and taught by Professor David Waite of Butler University, and an introductory level MBA accounting course, designed and taught by Professor Richard Rogers of the Kelley School of Business and the distance MBA Kelley Direct program. During a period of about two months each of the professors developed six learning objects for their courses. The design process will continue until both feel that their courses are complete. It is anticipated that each of the courses will contain about 50 learning objects. 


\section{LEARNING OBJECT TEMPLATES}

To date, the professors involved in this study have chosen four of the 39 templates and have designed a total of 12 learning objects. Additional templates have been chosen for future learning objects to be designed for their courses; however the focus of this paper is the existing learning objects each has designed. The four learning object templates are described below.

The Intelligent Paragraph Tool. One of the more difficult aspects of technology-mediated instruction is to assist students in acquiring writing skills and the ability to create meaningful short essay answers. The intelligent paragraph tool provides the student with a problem in which content, data, and interactive demonstration may be embedded. The student explores the information and is then asked to respond to a question or create a short piece of creative writing. The student is provided with a series of statements which are right, wrong, or do not pertain to the topic area. The student must not only pick the appropriate statements for the statement database, but then he/she must place them in the correct order, creating a meaningful essay. The student receives intelligent feedback on the answer and a grade if the instructor wishes.

The Click and Drag Tool. Many students learn best by visualizing content and developing a visual map of the specific material. The click and drag problem may contain an image of the content with labels that the student can learn by clicking on the sites in the diagram. After the student has developed mastery he/she can take a computer-graded test in which he/she must drag the correct labels to the correct sites in the diagram. This template may also be used to organize written material and create summaries of content. A student may organize content by clicking text items and dragging them to appropriate answer boxes. This template was used in this project as a tool for organizing written or spoken speeches.

The Time-Revealed Scenario Tool. Problem solving is an important way in which we establish mastery over content by using that content to solve a real-world problem. The time revealed scenario tool allows a student to work through a problem by making decisions based on content mastery and briefings in a timelayered approach. Each time layer represents a stage in a process that occurs over a period of time, and is driven by the decisions of the student. The student is first presented with a problem and information that allows him/her to make a decision on the best course of action to solve a problem. The selection triggers the next time layer of the problem and provides an updated situation for the student to examine. The student is then asked to make another decision to push towards a solution of the initial problem. There can be numerous outcomes depending on the decisions made by the student at each stage of the problem. The outcomes represent a spectrum of correct and incorrect strategies.

Evaluation Tool. In a number of subject areas students must develop evaluation skills. The evaluation tool allows students to evaluate a situation, performance, or text and compare their evaluations to that of their instructor. Intelligent feedback is provided to the students in order to help them understand where their evaluations differed from the correct evaluation and what aspects of the content they should review.

\section{THE COURSES AND DESIGN PROCESS}

In this section of the paper, the two professors will describe their courses and how each of them wanted to use technology to improve the students' experience in the courses. The applications built during this study may be found at the following web site: http://www.indiana.edu/ aln/. 


\section{A. Accounting}

This section of the paper reflects the design and adoption criteria of Professors Rogers and Magjuka. Professor Magjuka is the director of the Kelley Direct Program.

The Kelley School of Business (KSB) is consistently ranked in the Top 20 of U.S. schools of business for its undergraduate and graduate programs. KSB offers its programs on two campuses, Bloomington and Indiana University-Purdue University at Indianapolis (IUPUI). KSB offers four Masters of Business Administration (MBA) programs: a full-time, residential program in Bloomington; a part-time Evening program in Indianapolis on the IUPUI campus; an MBAA or MBA in Accounting program that is a fulltime, residential program in Bloomington; and the Kelley Direct OnLine MBA Program. While there are four programs offered by KSB, the School grants only one MBA degree to students. Therefore, for example, for the web-based, Kelley Direct OnLine MBA program there is no designation on the MBA degree that indicates whether a student enrolled in a MBA program online or residentially, full time or part time.

Kelley Direct: Through Kelley Direct (KD), the Kelley School of Business offers graduate, online degree programs that are designed to satisfy the needs of working professionals.

Kelley Direct offers online degree programs that maintain high quality standards within the School while offering a flexible program that addresses needs for adult learning and organizational development. Kelley Direct programs are designed to operate in a way that is similar, if not identical, to the part-time, Evening MBA program that KSB offers in IUPUI and to the residential MBA program in Bloomington. Special attention has been directed towards those issues associated with program quality in traditional MBA programs: admissions process, selection standards, curriculum design, program delivery and program evaluation.

The program is designed for professionals who wish to continue their employment while earning their MBA. The Kelley Direct Online MBA is a 48 credit hour part-time program that begins with a one-week in-residence course each year. The remainder of the program is web-based and asynchronous, allowing flexibility for executives to learn according to their schedule. The program utilizes a quarter system of 12 weeks each. Completion of the program takes two years if a student takes the maximum course load each quarter. On average, students complete the MBA program in twenty-eight to thirty-two months.

As a student in the online MBA, one will access text, audio, and video presentations, use bulletin boards and chat rooms along with traditional textbooks and case studies to complete team projects, take tests, and write papers. The class interaction is asynchronous with some synchronous elements, allowing students the flexibility to balance family and career demands.

Today, Kelley Direct has approximately one thousand degree-seeking students. Kelley Direct offers four online degree programs: Master of Business Administration (MBA), Master in Finance (MSF), Master in Global Supply Chain Management (MS GSCM), and Master in Strategic Management (MSSM). Within the MBA program there is a public MBA track, a corporate track and a dual-degree track with university partners. Anyone can apply for admission in the public MBA track. Corporate-sponsored MBA programs have been developed for John Deere, General Motors, United Technologies and Ingersoll-Rand. Finally, $\mathrm{KD}$ has recently entered into relationships with degree-granting academic units at other universities. Currently, KD has a KD MBA-Purdue University MS in Engineering dual-degree program. A KD MBAPurdue MS in Agricultural Economics program, and is launching a MBA-MS in Manufacturing 
Engineering with the University of Michigan. Approximately 350 students are enrolled in the public MBA program, 300 students are enrolled in the corporate-sponsored and approximately 100 in the university partner programs.

Accounting Course within Kelley Direct: The Accounting course within Kelley Direct was developed 5 years ago when online instruction was in its infancy. The first class had 13 students, with diverse backgrounds, with no expectation of prior accounting or online knowledge. This year over 200 students took the first accounting course, so significant changes in delivery technique were developed. In the early classes we relied heavy upon student/instructor correspondence to transfer knowledge. Now with four professors delivering material four times per year, significant use of technology is essential. Use of the interactive learning objectives described below dramatically improve the knowledge transfer process.

Rationale for Using Learning Objects: Technology has many meanings. At one time, it meant projecting PowerPoint slides of class notes. Today it means the active use of intelligent programs, often in a web delivery environment, to facilitate and reinforce the learning process.

How have we used technology to facilitate the instruction of accounting? Accounting is not intuitive to many students. Students misperceive that accounting is similar to mathematics; simply a formula driven process. This predisposition makes textbook based teaching methods difficult for many students. In fact, much of accounting is relational and even visual. Technology can dramatically enhance the understanding of accounting, but much has to be done to overcome student preconceptions of the subject.

Technology-based learning permits not only redundancy, which is a commonly relied upon tool for exam preparation, but more importantly, a number of "what if scenarios" can be built upon. Too many times instructors teach examples in a linear fashion: given $A$ and then $B$ please solve for $C$. Accounting exams then test by asking if you know $C$ and were given $A$, can you extrapolate to B. Technology-based instruction may allow students to continuously test their understanding of material by changing the conditions. To examine the applications described below, go to the following web site: http://www.indiana.edu/ aln/.

Click and Drag Tool: The integration of technology with the accounting model is an important development. Accounting can be like the art of painting; starting from simple basic brush strokes; by changing pressure and color, the simple becomes complex and starts to reveal a story.

Technology-based learning techniques allow students to interact with the building processes that are necessary for the creation of financial statements. We start from a simple equation of Assets = Liabilities + Owners Equity. We then describe a series of events that require recording, classification and, finally, statement preparation. With technology, we can display each decision made by the student, identify mistakes and demonstrate the outcome for each mistake or success. Real time feedback, coupled with a physical display of the outcomes for each decision, allow the student to visualize a somewhat nonintuitive process.

In our "demonstration case" we illustrate two different applications of the "what if" technique. First, we ask the student to identify the relationship between a journal entry and the Accounting equation. Traditional textbooks use labels to reinforce the relationship. The simple Flash program we created asks the student to identify and move the accounts into their correct classification. Although simple in design, classification of accounts is an essential first step to understanding the accounting process. This exercise 
can be expanded very easily so that dozens of accounts can be displayed and properly classified. When finished, an entire Balance Sheet appears and the connection between journal entries and financial statements is demonstrated.

The Time-Revealed Scenario Tool: In a second application we illustrate asking the student to identify two consequences to an action. First, we describe a situation:

LIMO borrowed $\$ 25,000$ from a bank at an interest rate of $12 \%$. If a company could re-finance the loan at $10 \%$ this would give the borrower several options. Using a simple time-revealed scenario the student is given choices of how to use the savings. They can shorten the duration of the loan or reduce their monthly payments over the same time horizon. The problem gives the student two options of how to use the savings. If the student selects option 1, then what are the strategic consequences to this action? Strategy one says we pay less interest while strategy two indicates we reduce the principle amount owed. Strategy one is correct and strategy two is flawed. The case then explains the difference between the two actions. The goal of the problem is to reveal consequences rather than just the correct answers.

Intelligent Paragraph Tool: Since accounting is both pattern-based and logical, to assess whether a student understands the accounting process, we set up a series of sentences which describe a process. Intelligent paragraphs have been introduced in other academic fields. In accounting we use the technique to determine whether a student can eliminate irrelevant information. When tested, many students can deduce correct answers knowing that one of choices presented is correct. In real problem-solving situations extraneous information has to be sorted out to focus on the actual problem being addressed. Intelligent paragraphs force the reader to concentrate on each part of a plausible scenario. One incongruent thought can invalidate the complete process.

A second dimension to the intelligent paragraph is the correct sequencing of the process. The accounting process must be completed in the correct order to make sure valid outputs are derived from the inputs. The intelligent paragraph can be used assess whether a student understands the correct progression of the process to affirm and reinforce their comprehension.

Our third illustration uses the intelligent paragraph. We give the students six sentences describing the concept of accrual accounting. Four of the sentences are accurate statements while two are false. The sentences are laid out in random order and the student is asked both to identify the correct statement, and then place it in the proper order. When completed, the paragraph describes the concept of accrual accounting in the context of the LIMO problem the students have been working on. The purpose of the exercise is to make sure that students are not simply figuring out the process of accounting, but also the logic of why events occurred in specific sequence. This problem was also developed with the click and drag template tool in a totally different format (see Web page cited above).

Evaluation of Web-Based Instruction: In business and accounting, one exciting outcome may be to reduce monotony. There may clearly be an entertainment value to technology. We have all experienced the curiosity of playing solitaire on the computer, yet we don't keep a deck of playing cards in our desk. Frequently we will open up a computer game, attempt to solve it and then return to the task at hand. Factors such as ease of access, keeping a game in memory, the animation factor, all contribute to why individuals access computer games where they would not have done the same activity in a traditional context. Education can easily become more flexible, easy to access and provide instant feedback. When we use animation and color we reduce monotony and therefore frustration. This may stimulate an interest to go further. 


\section{B. Speech and Communications}

This section of the paper reflects the adoption and design criteria of Professor David Waite.

Public Speaking at Butler University: The tradition of Butler's Communication Studies department favored a public speaking course. Public speaking has a long tradition at Butler stretching over several generations of professors, debaters, and students. For our department, a public speaking course emphasizing performance was a natural fit. Moreover, our decision was reinforced because this approach is still a dominant approach for first year students [1].

In addition, a public speaking approach seemed to fit the needs of our audience. The students at Butler differ widely in the types of communication that they see as most adapted to their future needs. Although Butler is a small, private university of just under 4,000 undergraduates, the school is complex. Butler consists of five colleges: Liberal Arts and Sciences, Education, Business, Pharmacy, and Fine Arts. Each has a slightly different view of what aspect of communication would be relevant to their careers.

Finally, we justified our decision by defining public speaking very broadly. We developed the stock issues derived from debate and speech competition to persuasive speeches using some variations on the problem-solution-advantages. This formula could be used in many different situations, from persuasive interviews with clients and patients, to decision-making groups and teams, to boardroom presentations, and to formal speeches.

The Role of Technology in the Public Speaking Course: A major determinant of the shape of "The Competent Speaker" in Butler's basic public speaking class was the decision to make the class webbased. Our web-based course is not "distance learning." Instruction still takes place within the classroom. Rather it is a more sophisticated version of various classroom management tools such as BlackBoard ${ }^{\mathrm{TM}}$ or WebCTTM.

Over the past year and one-half, Butler's Department of Communication Studies has worked with Kendall-Hunt Publishing to develop and implement a comprehensive package for our basic public speaking course. Our decision to partner with an experienced developer of academic (and Web-based) materials provided us with a certain unique advantages. Kendall/Hunt handled most of the technical responsibilities such as coding, copyediting, permission clearing, formatting, and site building. In addition, we received guidance on effective methods to integrate e-learning and Web design strategies. Small universities like Butler do not have the resources through our computer support staff to create or maintain a site.

Butler's decision to develop a course Web site was based upon a number of considerations. One widely discussed rationale is inevitability. Students raised with Internet technology make the trend toward integrating technology into the classroom unstoppable [2].

A more positive viewpoint would be that new communication technologies are, as Edmund Carpenter called them, "new languages," spoken by our students and we must learn this new language in order to communicate [3, 4]. Of course, not all students are computer literate and, even for those who are, instructors have an obligation to explain technology as a communication concept, develop students' technology skills, and provide an understanding of how computer-mediated technology is a part of students' everyday lives [5]. 
At Butler, improved standardization was an attractive reason for developing a course utilizing electronic technology. The ability of the department to serve the entire student body is made possible only through the use of adjunct professors. The increased size of the entering class over the last ten years has compounded our problems. One last push towards standardization has been the successful use of student tutors through our Speaker's Lab. Since the student tutors must work with students from all sections, large idiosyncrasies among sections and assignments are problematic. The web-based element of the course is a way of ensuring more consistency among the various sections. To examine the applications described below, go to the following web site: http://www.indiana.edu/ aln/.

Evaluation Tool: All students and instructors complete a rating form for each speech heard in class. This provides feedback for the speakers. More significantly, we used the rating system as a teaching device. Training students to use the form should simultaneously teach them to be better speakers. As a student understood what observed behaviors exhibited excellence in speaking, so they understood what behaviors they should exhibit to be rated as an excellent speaker. As we trained students to use the form, we were also training students to create, organize, and deliver speeches.

Click and Drag Tool: In persuasive speeches, outlines serve as a method to test our organization and reasoning. One must introduce a central argument and then develop it with coordination of statements of equal importance and subordinate statements that may provide detail or clarification of the main theme. The click and drag tool provides an opportunity to create an organizational outline, into which, statements that represent the central theme and subordinate statements are placed. The student is provided with a series of statements and an organizational outline. The outline consists of answer boxes laid out to represent a particular organizational scheme. Each of the statements must be dragged into the correct box in the organizational scheme.

Intelligent Paragraph Tool: Another approach to the organization of persuasive speeches is to use the intelligent paragraph tool to allow the student to place statements in an order that reflects a sound organizational structure. In this case, six statements are provided to the student. Four of the statements can be combined to create a well organized persuasive speech. Four answer boxes are provided to the student, although the boxes are not labeled with a particular organizational scheme as is the case in the click and drag application. The student must therefore implicitly understand the organizational scheme needed to create a well crafted persuasive speech.

\section{Process and Cost Analysis}

Design Process: The design of the learning objects discussed in this paper began with a brief meeting with each of the professors, during which each was given a short demonstration of the learning object templates. A demonstration disk containing all of the templates, working examples of each, and a PDF file containing explanations of all of the templates was given to each professor. After giving them two weeks to examine the learning object templates, a design meeting was then scheduled with each professor, and four learning objects were designed over a period of about two hours.

Each preliminary design was then executed from the appropriate template. Excluding the time spent creating original graphics, the preliminary prototype for each of the learning objects was created in less than 40 minutes. The prototype designs were then presented to the professors to test and determine what modifications they wished to make in the design. Modifications were made according to the directions of each professor and the final design was presented to the professor. The modification process took about 10-20 minutes for each of the learning objects. The total execution time for each of the learning objects was less than one hour. 
The templates for each of the learning objects took at least several days to create. To recreate the source code for each would require 6-24 hours for each. Thus, the use of the templates appears to reduce learning object development time by about $90 \%$.

Cost Analysis: It has been estimated that the cost of developing a learning object is between $\$ 10,000$ and $\$ 15,000$ by Bates [6]. Using data from the Chronicle of Higher Education on faculty salaries and the estimated average time spent by the professors in this study, the total cost of design was $\$ 141$. Using an average salary for a well trained, senior multimedia programmer of $\$ 45 / \mathrm{hr}$. the average cost of executing the design of the learning objects in this study was $\$ 43.50$. The average total cost of creating the learning objects in this study was $\$ 184.50$.

If we assume that the average Web or technology-mediated course contains about 50 learning objects (4 learning objects per module for a 13-14 week course), the total cost of creating a full compliment of learning objects for a single course would be $\$ 2,175$, excluding the professor’ time.

\section{Templates and Learning Management Systems}

The TALON/nPower templates are currently used by over 30 universities in the U.S., Europe, Asia, Africa, and the Middle East. Many use commercial learning management systems (LMS) such as WebCOM, Blackboard, or Web CT, and others have systems developed internally. A few have no learning management systems, and use the TALON/nPower templates to create learning objects to supplement course material in traditional or correspondence type courses.

Those universities that use commercial or internally developed learning management systems have experienced no difficulty in including learning objects created from the TALON/nPower templates because they need only to include a hyperlink from the course to the Shockwave file that is the executable file for the learning object. Any LMS that provides for links to external Web sites or files residing on the institution's server can utilize these learning objects. No LMS has been encountered yet that cannot accommodate the TALON/nPower learning object files. In most cases, the shockwave files for the learning objects created by TALON/nPower reside on the institution's server.

Butler University adopted the WebCOM learning management system developed by Kendall-Hunt Publishing. This system represents a new broader approach to technology-mediated instruction that includes creation of customized textbooks, Web sites, and learning objects designed specifically for a particular course. The instructor(s) of the course design(s) all materials with the assistance of a development team from the publisher. Although the instructor and institution have full control over the creation and management of the course materials, they have no responsibility to execute, distribute, or maintain the materials. Kendall/Hunt executes the site based upon the course (and section-specific needs) maintains the site each semester, and hosts it on dedicated servers.

WebCOM utilizes the TALON/nPower learning object templates to create the learning objects integrated within the courses it hosts. This allows the institution using WebCOM to incorporate a rich assortment of multimedia learning objects without having to maintain a costly multimedia staff. The cost for accessing the course Web site (learning management system) and other traditional materials are paid by the student. This typically results in student costs which are consistent or lower than a traditional textbook alone. In addition, the instructor/designer and institution receives royalty income from each course.

The Kelley-Direct program has recently adopted a commercial platform called ANGEL. For the first 
years of its existence Kelley-Direct used an internal Indiana University LMS that experienced numerous malfunctions and periods of down time. ANGEL is an open Enterprise Course Management System. ANGEL is designed to complement existing traditional courses and deliver distance courses. ANGEL contains shared resource libraries and databases that allow instructors to share and reuse learning materials. The instructor creates and loads course materials using a simple tool set that allows word processing documents, images, and PowerPoint presentations. Links to multimedia exercises, such as the learning objects created with the TALON/nPower system, are easily incorporated into the system even if the Shockwave files are hosted on a different server than the course. Institutions using ANGEL can host their own courses or use the ANGEL servers. The cost of ANGEL is paid by the institution rather than directly by the student and the instructor/designer receives no royalty income.

\section{LESSONS LEARNED}

This project shows that instructors with little or no programming experience can use sophisticated multimedia tools if they are provided with templates that are easy to understand and use. Talented instructors are good learning object designers because they have designed class activities in their traditional classes for years. Their design skills and intuitive knowledge of pedagogy have made them successful instructors. Instructor/designers must understand how the student visualizes content in order to create an environment in which the student can place the content within the context of the subject matter area. To create a successful learning object, the instructor must understand the misperceptions and difficulties the student may experience and create learning environments in which the student can address those misperceptions.

The professors in this study adapted the templates to their course materials with no difficulty; however both tended to select a limited number of templates and use those exclusively. Once each professor designed a few learning objects with one or more templates, a "comfort level” was created that tended to restrict the professor's interest in some of the other templates This tends to limit the richness of the multimedia environment. It is possible that more extensive training for professors about the more complicated TALON/nPower templates would result in the adoption of a more varied array of templates.

A surprising outcome of this project was the ability of the professors to create new applications, which were later developed as templates. The two professors in this study had little or no technical knowledge of or experience with multimedia, and yet their design skills allowed them to create novel applications that could only be developed by content mater experts. The evaluation tool is an example of this process. One of the important aspects of the public speaking course is evaluation of speeches and comparisons of the student assessment with the correct assessment provided by the instructor. The evaluation tool was developed after the initial design meeting, and was created by taking several functions from existing templates and creating new source code to create the new template.

One of the early adopters of the TALON/nPower learning object suite, and currently an important codeveloper, is the Open University of Malaysia (OuM). Their experiences after a year of use have been:

1. Templates are reusable when the learning outcomes match those templates, and, in terms of cost and time, a saving of up to $80 \%$ is possible with no adverse effects on the quality of the learning material. The reusability factor is also affected by the expertise provided by instructional designers and multimedia programmers. The short-term gains are immense.

2. Where learning outcomes do not match existing instructional templates, and creation of new templates is imminent, there is some savings in terms of time and money in the short-term. 
However, in the long-term, the organization gains much in terms of increase in value of organizational knowledge, as well as increase in the number of instructional templates.

\section{REFERENCES}

1. Morreale, S. P. et al. "The Basic Communication Course At U.S. Colleges and Universities: VI," Basic Communication Course Annual (NCA) 11: 9, 1999.

2. Samoriski, J. The Internet, Children, and Education, Issues in Cyberspace: Communication, Technology, Law, and Society on the Internet Frontier, 325. Boston: Allyn and Bacon, 2002.

3. Carpenter, E. "The New Languages," Explorations in Communication. Edmund Carpenter and Marshall McLuhan, eds. Boston: Beacon Press, 1960.

4. Haynes, W. L. "Public Speaking Pedagogy in the Media Age," Communication Education 39(2): 90, April 1990.

5. Witmer, D. F. "Introduction to Computer-Mediated Communication: A Master Syllabus for Teaching Communication Technology,” Communication Education 47(2): April 1998.

6. Bates, A. W. Managing Technological Change, 286. San Francisco: Jossey Bass Publishers, 1999.

\section{ABOUT THE AUTHORS}

Jeremy Dunning is the president of Arjuna Multimedia, professor of geology at Indiana University, and the developer of the TALON learning object template system described in this paper.

Richard Rogers is a professor in the Kelley School of Business at Indiana University.

Richard Magjuka is a professor in the Kelley School of Business at Indiana University and Director of Kelley Direct.

David Waite is a professor of Communications Studies at Butler University.

Thomas Gantz is Senior Vice President of Kendall/Hunt Publishing.

Keith Kropp is the Editorial Coordinator of Digital Publishing for Kendall/Hunt Publishing.

Abtar Kaur is a professor at Open University of Malaysia.

Ari Vidalli is the Principal Partner of Envisage Corporation.

Thomas Hunt is a senior programmer at Indiana University.

Larry Vandermolen is a senior instructional designer at Indiana University. 